Letter to the Editor

\title{
Artefacts of ganglion cell complex analysis in eyes with vitreomacular traction syndrome
}

Hugh J . Slifirski BSc, ${ }^{1,2}$ Queena Qin MBBS, ${ }^{1,3,4}$ Mathew Rawlings BSc(Hons) ${ }^{1,5}$ and Devinder S. Chauhan $\mathrm{MD}^{1}$

1. Vision Eye Institute, 852 Whitehorse Road, Box Hill, Victoria 3128, Australia

2. University of Melbourne, Australia

3. Royal Adelaide Hospital, Australia

4. University of Adelaide, Australia

5. Deakin University, Australia

Correspondence: Devinder S. Chauhan, Vision Eye Institute, 852 Whitehorse Road, Box Hill, Victoria 3101, Australia

Email: devinder@me.com

Received 7 April 2020; accepted 13 April 2020

Funding sources / Financial disclosure: None

Conflict of interest: None

This is the author manuscript accepted for publication and has undergone full peer review but has not been through the copyediting, typesetting, pagination and proofreading process, which may lead to differences between this version and the Version of Record. Please cite this article as doi: 10.1111/ceo.13765

This article is protected by copyright. All rights reserved. 
Optical coherence tomography (OCT) is useful in the diagnosis and monitoring of macular disease ${ }^{1}$. OCT offers high-resolution measurements of the ganglion cell complex (GCC), comprised of the ganglion cell layer (GCL) and the inner plexiform layer (IPL) ${ }^{2}$. Ganglion cell analysis (GCA) is a tool in Zeiss Cirrus HD proprietary review software that measures GCC thickness, which used in diagnosis and monitoring of disease. However, its viability is limited by artefacts and the reproducibility of segmentation.

This letter illustrates a previously undescribed artefact related to vitreomacular traction (VMT) syndrome. VMT it is fairly common and often changes, either by spontaneous resolution or following surgery ${ }^{3}$. As the fovea is an important landmark in automated retinal thickness assessment ${ }^{4}$, an improperly centred fovea, secondary to VMT, on the automated foveal localisation (AFL) tool may result in abnormal thickness map artefacts that lead to difficulties in managing pathology 5 .

We investigated 62 scans of otherwise healthy eyes affected by VMT, collected consecutively from a retinal clinic between October 2012 and J anuary 2017. All participants had given written consent for their de-identified images to be used for research and chairman's approval was granted from the Royal Victorian Eye and Ear Hospital Human Research and Ethics Committee.

Upon inspection of VMT GCA scans, we noted that some GCA maps had abnormal patterns that seemingly indicate eccentric thinning of the ganglion cell complex, despite eyes being free from any other retinal pathology. Upon inspection of the corresponding horizontal B-scans of abnormal GCA images, we observed that segmentation of images was often false (Figure 1). The purple line typically delineates the inner border of the GCL and the yellow line the outer border of the IPL. In such instances, there is an eccentric localisation of the AFL, relative to the 
anatomical fovea, and an assumed pattern of GCC thickness is displayed by the software. That is, the GCC is always absent at the site of the AFL and increases in thickness radially outwards; visual inspection of the scans often shows this segmentation to be false.

In normal eyes, the thinnest section of the macula is the foveola, an anatomical feature utilised by the AFL tool. In VMT, vitreous adhesion affects the contour of the macula, resulting in the foveola no longer being its thinnest part. The automated software consequently misidentifies an eccentric location as the foveola. However, it appears that a standardised pattern of GCC thickness is assumed by the GCA software, in which the GCC is absent centrally in the normal fovea, and initially increases in thickness radially outwards. Therefore, GCA is unable correctly to perform segmentation, producing these artefactual patterns of abnormality. When the AFL determines the foveal centre to be away from the true location, this pattern is projected onto the OCT at the site of the presumed foveal centre, with a central GCC thickness of zero, in spite of it being visible on inspection.

We found that through manipulation of AFL to the anatomical location of the foveola, some of the abnormal GCA maps could be rectified as segmentation was then performed correctly (Figure 2). Interestingly, in scans of normal eyes, unaffected by VMT, these artefacts could be recreated by manually shifting the AFL eccentrically. Therefore, we know that this artefact is caused by eccentric placement of the AFL.

In practice, the findings of this study behove clinicians, when confronted with one of the GCA patterns described, to inspect the cross-sectional OCT scan at the fovea as well as both the automated foveal localisation and segmentation of the software. If 
there are signs of VMT, or the AFL is eccentric, then the GCA map should be used with caution in the knowledge of possible artefacts induced. 


\section{REFERENCES}

${ }^{1}$ Murthy R, Haji S, Sambhav K, Grover S, Chalam K. Clinical applications of spectral domain optical coherence tomography in retinal diseases. Biomed J.

2016;39(2):107-120. doi:10.1016/j.bj.2016.04.003

2 I shikawa H, Stein DM, Wollstein G, Beaton S, Fujimoto JG, Schuman JS. Macular segmentation with optical coherence tomography. Invest Ophthalmol Vis Sci 2005;46(6):2012-7.

3 Smiddy WE, Michels RG, Green WR. Morphology, pathology, and surgery of idiopathic vitreoretinal macular disorders. A review. Retina. 1990; 10(4):288-96. ${ }^{4}$ Liefers B, Venhuizen F, Schreur $V$ et al. Automatic detection of the foveal center in optical coherence tomography. Biomed Opt Express. 2017;8(11):5160. doi:10.1364/boe.8.005160

${ }^{5}$ Legarreta JE, Gregori G, Punjabi OS, Knighton RW, Lalwani GA, Puliafito CA. Macular thickness measurements in normal eyes using spectral domain optical coherence tomography. Ophthalmic Surg Lasers Imaging. 2008;39(4 suppl):S43-S9.

\section{FIGURE LEGENDS}

Figure 1: Incongruence of automated foveal localisation with visual inspection of optical coherence tomography B-scans.

Figure 2: Examples of rectification of artefact by automated foveal localisation manipulation. The green numbers indicate the magnitude of the manipulation in the horizontal and vertical planes and the red number indicates the direction of the manipulation. 


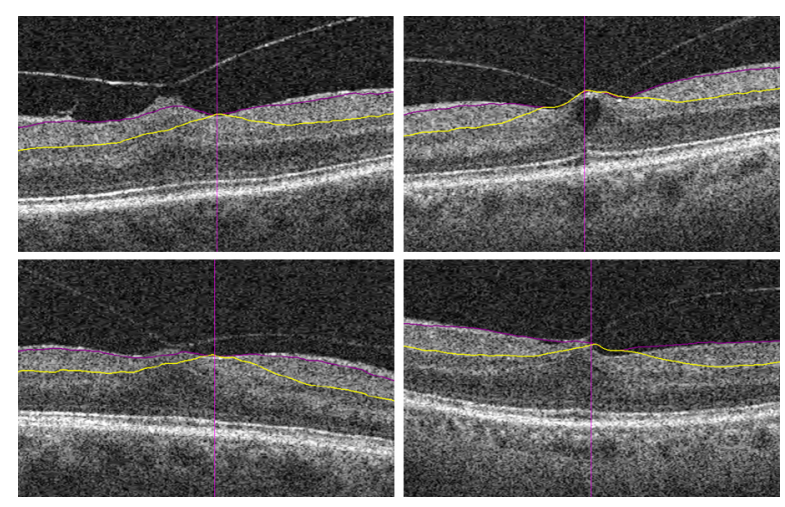

CEO_13765_CE0-20-04-0450 figure 1.jpg

This article is protected by copyright. All rights reserved. 


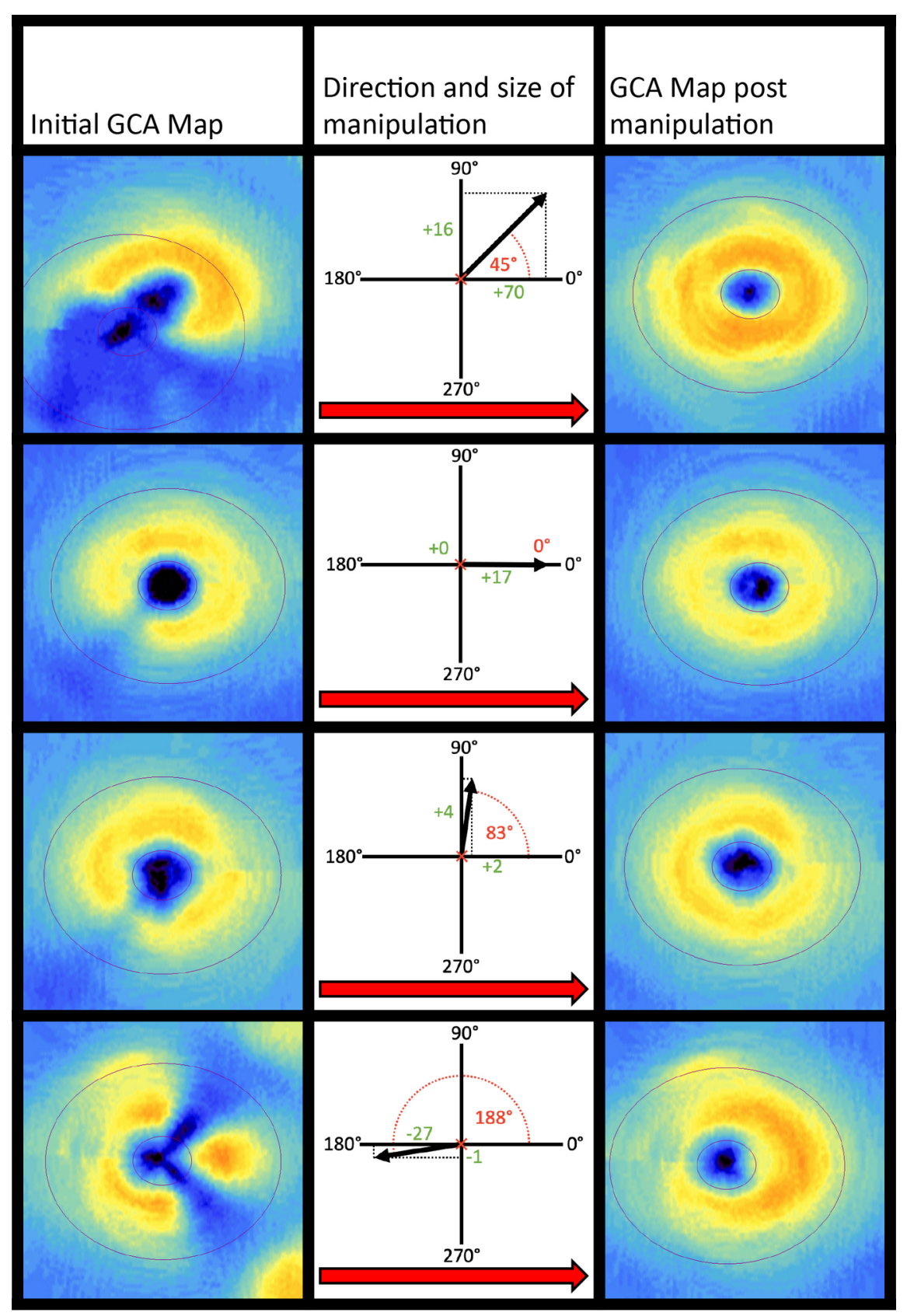

CEO_13765_CE0-20-04-0450 figure 2.jpg 


\section{University Library}

\section{- M M N E R VA A gateway to Melbourne's research publications}

Minerva Access is the Institutional Repository of The University of Melbourne

Author/s:

Slifirski, HJ;Qin, Q;Rawlings, M;Chauhan, DS

Title:

Artefacts of ganglion cell complex analysis in eyes with vitreomacular traction syndrome

Date:

2020-05-04

Citation:

Slifirski, H. J., Qin, Q., Rawlings, M. \& Chauhan, D. S. (2020). Artefacts of ganglion cell complex analysis in eyes with vitreomacular traction syndrome. CLINICAL AND EXPERIMENTAL OPHTHALMOLOGY, 48 (6), pp.844-847. https://doi.org/10.1111/ceo.13765.

Persistent Link:

http://hdl.handle.net/11343/275716 